\title{
Construção mediada e colaborativa de instrumentos de avaliação da aprendizagem na escola inclusiva
}

\author{
Alessandra de Fatima Giacomet Mello* \\ Regina Célia Linhares Hostins**
}

\section{Resumo}

O artigo tem o propósito de discutir a potência da construção mediada de instrumentos de avaliação de aprendizagem entre professores do ensino comum e do Atendimento Educacional Especializado - AEE para a inclusão escolar. Argumenta-se que a avaliação tem sido um dos gaps nas práticas de escolarização de alunos público-alvo da educação especial na escola comum, gerada em grande parte pela persistência de determinadas formas de pensamento e de organização da cultura escolar (Prosser, 1999; Dussel, 2014), as quais aprofundam a cisão entre o trabalho do professor do $\mathrm{AEE}$ e o da sala comum de ensino. As práticas de avaliação no AEE e na sala comum têm sido exiladas uma das outras e, nesse contexto, também se exila e se torna invisível o aluno. Essa problemática conduziu a um trabalho de pesquisa colaborativa, para a construção coletiva e mediada do Plano Colaborativo de Atendimento Educacional para uma aluna com deficiência intelectual do $6^{\circ}$ ano do ensino fundamental. Participaram da investigação sete professores dos anos finais do ensino fundamental, - Língua Portuguesa, Geografia, História, Matemática, Arte, Ciências, Educação Física - e dois da educaçáo especial que juntos desenvolveram dinâmicas de estudo e definição de conceitos, procedimentos e instrumentos diferenciados de avaliação pedagógica do aluno com deficiência matriculado em suas classes. Os resultados evidenciaram experiências compartilhadas de discussão sobre o modo de aprendizagem do aluno com deficiência intelectual e a concepção coletiva de um instrumento de planejamento e avaliação dimensionado para a sua efetiva participação e sucesso na escola de educação básica.

Palavras-chave: Inclusão escolar; Avaliação da aprendizagem; Colaboração.

\footnotetext{
* Doutoranda da Universidade do Vale do Itajaí (UNIVALI), Itajaí, Santa Catarina, Brasil.

** Professora doutora da Universidade do Vale do Itajaí (UNIVALI),Itajaí, Santa Catarina, Brasil.
} 


\section{Mediated and collaborative construction of learning assessment tools in inclusive school}

\section{Abstract}

This article aims to discuss the power of the mediated construction of learning assessment tools among teachers of the common teaching and the Specialized Educational Assistance - SEA for the school inclusion. It is argued that the assessment has been one of the gaps in the schooling practices of public-targeted pupils of special education in the common school, generated in large part by the persistence of certain forms of thought and organization of school culture (Prosser 1999, Dussel, 2014), which deepen the split between the work of the ESA teacher and that of the common teaching classroom. The assessment practices in ESA and in the common classroom have been exiled from one another and, in this context, the student is also exiled and becomes invisible. This problem led to a collaborative research work for the collective and mediated construction of the Collaborative Plan for Educational Service for a student with intellectual disability in the 6th year of elementary school. The investigation had the participation of seven teachers from the final years of elementary school - Portuguese Language, Geography, History, Mathematics, Art, Science, Physical Education - and two from special education, who together developed study dynamics and concept definition, differentiated procedures and tools for pedagogical assessment of the student with disabilities enrolled in their classes. The results evidenced shared experiences of discussion about the way of learning of students with intellectual disabilities and the collective conception of an instrument of planning and assessment designed for their effective participation and success in the elementary school.

Keywords: School inclusion; Learning assessment; Collaboration.

\section{Construcción mediada y colaborativa de instrumentos de evaluación del aprendizaje en la escuela inclusiva}

\section{Resumen}

El artículo tiene el propósito de discutir la potencia de la construcción mediada de instrumentos de evaluación de aprendizaje entre profesores de la enseñanza común y del Servicio Educatico Especializado SEE para la inclusión escolar. Se argumenta que la evaluación ha sido uno de los gaps en las prácticas de escolarización de alumnos público-objetivo de la educación especial en la escuela común, generada en gran parte por la persistencia de determinadas formas de pensamiento y de organización de la cultura escolar (PROSSER, 1999; DUSSEL, 2014), que profundizan la escisión entre el trabajo del profesor del SEE y el de la sala común de enseñanza. 
Las prácticas de evaluación en el SEE y en la sala común han sido exiliadas una de las otras y, en ese contexto, también se exilia y se vuelve invisible el alumno. Esta problemática condujo a un trabajo de investigación colaborativa, para la construcción colectiva y mediada del Plan Colaborativo de Atención Educativa para una alumna con discapacidad intelectual del $6^{\circ}$ año de la enseñanza fundamental. Participado en la investigación de siete profesores de los últimos ańos de la escuela primaria - Lengua Portuguesa, Geografía, Historia, Matemáticas, Arte, Ciencia, Educación Física - y dos de la educación especial que juntos han desarrollado dinámicas de estudio y definición de conceptos, procedimientos e instrumentos diferenciados dela evaluación pedagógica del alumno con discapacidad matriculado en sus clases. Los resultados evidenciaron experiencias compartidas de discusión sobre el modo de aprendizaje del alumno con discapacidad intelectual y la concepción colectiva de un instrumento de planificación y evaluación dimensionado para su efectiva participación y éxito en la escuela de educación básica.

Palabras-clave: Inclusión escolar; Evaluación del aprendizaje; Colaboración.

\section{Introdução}

A escola inclusiva, solidificada com políticas educacionais que reafirmam o compromisso com a diversidade humana, tira do aluno o foco da incapacidade de aprender e o direciona para formas e estratégias dinâmicas de escolarização e aprendizado. Mas estar na letra da Lei nem sempre é garantia de efetivação desses pressupostos.

Ao tratar da escolarização de alunos com deficiência na escola comum, a letra da Lei e a cultura escolar ainda bailam em desarmonia, com passos desajustados e em ritmos diferentes. Dussel (2014) afirma que apesar de profusas tentativas de reforma do pensamento e da organização das escolas, a estrutura básica da escolarização permanece praticamente inalterada, como percebe-se na persistência do modo

$$
\begin{aligned}
& \text { [...] como as escolas dividem o tempo e o espaço; como classifi- } \\
& \text { cam os alunos e os alocam em grupos [...] como dão forma a qual } \\
& \text { conhecimento que deve ser ensinado em disciplinas escolares, e } \\
& \text { como eles estruturam a promoção e o sistema de créditos dos alu- } \\
& \text { nos [...] (DUSSEL, 2014, p.255). }
\end{aligned}
$$

Tais práticas ainda permanecem após 10 anos da Política Nacional de Educação Especial na Perspectiva da Educação Inclusiva (PNEEPEI) (2008) na qual se defende que a organização das escolas "[...] passa a ser repensada, implicando uma mudança estrutural e cultural da escola para que todos os estudantes tenham suas especificidades atendidas" (BRASIL, 2008, p.1). Porém, tais mudanças não têm acontecido como preconizado e a cultura escolar pré-políticas de inclusão ainda se encontra fortemente arraigada ao éthos escolar.

Sendo a cultura escolar como define Prosser (1999, p.14) "[...] uma força invisível e não observável atrás das atividades escolares [...] [e] tem tanto representação concreta na forma de artefatos e normas de comportamento, quanto jargões, metá- 
foras e rituais implicitamente mantidos", basta olhar para as escolas públicas atuais para que se confirme que os elementos da sua cultura ainda precisam acertar o passo junto aos princípios da inclusão para que se possa realizar, de fato, a escolarização dos alunos da educaçáo especial inclusos em suas turmas regulares.

Apesar do fim último do ensino comum e especial serem o mesmo: a escolarização dos alunos, na realidade a práxis acontece em dimensōes diferentes. A relação que se estabelece entre salas do ensino comum e salas de Atendimento Educacional Especializado (AEE) ainda é de dualidade. Os espaços, os tempos e a avaliação postos em nossas escolas comuns são, a princípio, organizados e estruturados para a escolarização coletiva, assim como organizados para alunos "uniformes". Ao se deparar com um aluno com deficiência, portanto com necessidades fora das suas "práticas padrão" (SKRTIC, 2014, p. 183), a escola enquadra essas necessidades ao já estabelecido em sua cultura escolar e encaminha-o ao AEE como forma de resolução do problema e assim justifica a impossibilidade de mudar-se e adaptar-se às necessidades, ou seja ratifica seus espaços e tempos instituídos com o encaminhamento à educação especial que tem em sua gênese outras formas de organizaçáo, funcionamento e atuação.

Os espaços e os tempos das salas comuns são culturalmente organizados para o ensino e aprendizagem coletivos, de forma homogeneizada, em que um professor ensina a todos da mesma forma e consequentemente espera-se que todos aprendam também da mesma forma. Todo o processo está centrado na aprendizagem de conteúdos disciplinares e a avaliação, por sua vez, nos resultados. Já os espaços do $\mathrm{AEE}$ - separados do ambiente comum - caracterizam-se pela individualização do ensino no qual o apoio pedagógico é ofertado em atendimentos individualizados ou em pequenos grupos (BRASIL, 2009). Nestes, o processo de escolarização centra-se nos recursos de acesso ao currículo como materiais didáticos e pedagógicos, mobiliários, equipamentos e sistemas de comunicação e informação (BRASIL, 2009).

A arquitetura da sala de aula comum é preparada para uma prática que raramente considera as necessidades específicas dos alunos. Nela se observa a indicação precisa dos espaços individuais do professor e dos alunos, com carteiras enfileiradas, em frontalidade com o quadro negro e o professor em posição central, de forma que todos os alunos tenham que executar a mesma atividade a um só tempo (FARIA FILHO e VIDAL, 2000, p.25). No AEE, por sua vez, o professor tem mobiliários e carteiras dispostos de formas variáveis, de acordo com as necessidades de um contato mais próximo com o aluno ou grupo (SILVA, HOSTINS e MENDES, 2016).

Outra característica da relação dual entre o ensino comum e a educação especial são os tempos escolares, entendidos como aparato que também constitui o éthos escolar. O ensino comum tem sua organização marcada pela repartição temporal do processo de ensino e aprendizagem. Com a distribuição diária, semanal e/ou em unidades de tempo bimestral, semestral do conteúdo organizado sequencialmente para o desenvolvimento de atividades, impondo o fracionamento do conhecimento em disciplinas e no consequente divórcio entre áreas do conhecimento.

Em contrapartida, os tempos no AEE não são fixos ou delimitados com rigo- 
rosidade. É sabido que todo o processo de ensino e aprendizagem nestes programas se dá no tempo próprio do aluno, não há divisão de áreas do conhecimento enquadradas em grade semanal, nem calendário para feedback de conteúdos. Ademais, a avaliação, é ponto fulcral nessa relação entre o ensino comum e o especial, e se constitui numa das formas "de fazer a e do fazer-se da escola e de seus sujeitos" (FARIA FILHO e VIDAL, 2000, p. 21, grifos dos autores) destacando-se como um dos gaps da escolarização dos alunos da educação especial na escola comum.

A problemática das condições de escolarização do aluno com deficiência inserido no ensino comum, em especial, a avaliação da aprendizagem destes sujeitos se insere no objetivo deste trabalho que é também um excerto de estudos e reflexóes que vêm sendo realizados pelo Observatório de escolarização de alunos com deficiência intelectual e do Observatório de Politicas Educacionais do Programa de Pós-Graduação em Educação da Universidade do Vale do Itajai. Mais especificamente, objetiva-se aqui discutir a potência da construção mediada e colaborativa de instrumentos de avaliação de aprendizagem por professores do ensino comum e do Atendimento Educacional Especializado - AEE para a inclusão escolar.

\section{O plano de atendimento educacional: a letra da Lei}

Ao orientar os sistemas de ensino para promover respostas às necessidades educacionais dos alunos com deficiência no AEE, a PNEEPEI, orienta a atuação articulada entre a educaçáo especial e o ensino comum no atendimento desses alunos, reforçando a importância de práticas colaborativas. A Resolução 04/2009, que institui as diretrizes operacionais para o AEE acentua, em seu Artigo $9^{\circ}$ que "elaboração e a execução do plano de AEE são de competência dos professores que atuam na sala de recursos multifuncionais ou centros de $\mathrm{AEE}$, em articulação com os demais professores do ensino comum, [...]" (BRASIL, 2009, p.2).

O documento no artigo 10, item IV, orienta que a organização do plano do AEE deve conter "[...] a identificaçáo das necessidades educacionais específicas dos alunos, a definiçáo dos recursos necessários e das atividades a serem desenvolvidas; " assim como a articulaçáo do professor do AEE com os professores da sala de aula comum visando a promoção e a participação dos alunos nas atividades escolares (BRASIL, 2009, p.2).

Percebe-se nos textos legais oficiais que a elaboraçáo do Plano de Atendimento Educacional Especializado (PAEE) é responsabilidade do AEE em articulação, em colaboraçấo com o professor do ensino comum. As políticas educacionais vigentes o apresentam como de competência dos professores da educação especial, porém não determinam que este deve transitar entre o ensino comum e a educação especial, ficando claro sua aplicabilidade especificamente ao AEE.

Com base em vários estudos de especialistas na área de Plano de Atendimento Educacional Especializado (GLAT e PLETSCH, 2009, 2013; GLAT, VIANNA e REDIG, 2012; PLETSCH, et all, 2010; PLETSCH e GLAT, 2012) e em toda a variante nominata deste Plano, a saber: Plano Educacional Individualizado (PEI); Plano de Desenvolvimento Psicoeducacional Individualizado (PDPI); Plano de De- 
senvolvimento Educacional Individualizado (PDEI); e o próprio Plano de Atendimento Educacional Especializado (PAEE) instituído pela Resolução 04/2009 (BRASIL, 2009), é que se buscou subsídios para a proposição do Plano Colaborativo de Atendimento Educacional na pesquisa ora relatada, como "estratégia para contemplar a diversidade do alunado presente, hoje, em nossas escolas e, principalmente, como resposta educativa aos casos de alunos com deficiência [...]" (PLETSCH e GLAT, 2013, p. 18).

Dentre os vários elementos que promovem a prática pedagógica inclusiva, considera-se que o Plano de Atendimento Educacional se caracteriza como uma forma de intervenção pedagógica capaz de agir interativamente entre os objetivos de aprendizagem do aluno tanto na educaçáo especial quanto no ensino comum.

Desse modo, tendo por referência os estudos citados e as diretrizes legais como a PNEEPEI (BRASIL, 2008), a Resolução 04 de 2009 (BRASIL, 2009), o Decreto Presidencial 7611 de 2011 (BRASIL, 2011) buscou-se construir um instrumento que traduzisse a efetiva colaboração entre professores envolvidos com o processo de ensino-aprendizagem do aluno com deficiência no contexto da escola inclusiva. Mediante experiência da pesquisa-formação com professores dos anos finais do ensino fundamental e professores do AEE, foi concebido o Plano Colaborativo de Atendimento Educacional (PCAE). Plano este que busca tornar-se um insumo para o planejamento e as açóes compartilhadas dos professores do AEE e do ensino comum no propósito de garantir a todos os seus alunos o acesso ao currículo e consequente sucesso na aprendizagem.

\section{Caracterização da metodologia}

A pesquisa, de caráter qualitativo e colaborativo permitiu as pesquisadoras atuarem, ao mesmo tempo, nos campos da pesquisa e da formaçáo docente. Definiu-se pela pesquisa colaborativa, uma vez que dessa forma seria possível o "[...] pensar-agir para criar possibilidades de compartilhamento das ideias, percepçóes, representaçóes e concepçóes, com o propósito de criar condiçóes de questionar, negociar e reelaborar" (BANDEIRA, 2016, p. 27) o conhecimento.

A escolha dos sujeitos da pesquisa se deu a partir do seguinte critério: ser professor de aluno com deficiência intelectual incluso em uma turma do ensino fundamental (anos finais) e frequentando o AEE. Participaram da investigação sete professores de disciplinas dos anos finais do ensino fundamental, - Língua Portuguesa, Geografia, História, Matemática, Arte, Ciências, Educação Física - e dois da educaçáo especial que, juntos com os pesquisadores, desenvolveram dinâmicas de estudo e definiram conceitos, procedimentos e estratégias diferenciados de avaliação pedagógica de uma aluna com deficiência intelectual (que por razôes éticas será chamada de Joana) matriculada em suas classes.

Estruturou-se a pesquisa-formação com a definição dos temas de estudo, em coerência com o objeto de investigação. Desse modo, foram organizados 6 encontros presenciais de 4 horas e mais 6 horas de estudos a distância, com a realizaçáo de atividades práticas na sala de aula, nas disciplinas de responsabilidade de cada um dos pro- 
fessores e nas quais a aluna referência para o estudo estava matriculada. Tais estudos e atividades tinham o propósito de produzir saberes e referenciais teórico-metodológicos que subsidiassem a investigação dos processos de ensino e aprendizagem da aluna com deficiência, tanto na sala de ensino comum como no AEE e que possibilitassem a construção mediada de instrumento de avaliação, a partir de práticas colaborativas entre professores e pesquisadoras.

O trabalho proposto para a formação, envolveu três momentos distintos, que se nutrem mutuamente - diagnóstico, análise crítica da situação e ação/decisão (Boterf, 1999). Desse modo, para a etapa do diagnóstico considerou-se a seguinte questáo: $\mathrm{O}$ que nós conhecemos sobre nossa aluna com deficiência intelectual? $\mathrm{Na}$ etapa da análise crítica indagou-se sobre: quais os instrumentos que existem para avaliá-la; qual a análise crítica que se pode fazer do Plano de Atendimento Educacional existente? E quais as possibilidades de redimensionar o olhar sobre a aprendizagem? Finalmente, na etapa da ação/decisão a questão norteadora foi: que conceitos, critérios e práticas devem ser levados em conta na construção mediada e colaborativa de um instrumento comum de avaliação, que contemple tanto o processo quanto o resultado da aprendizagem da aluna?

Essas questôes, descritas na sequência, definiram o processo de produção do Plano Colaborativo de Atendimento Educacional e foram alimentadas pelo estudo de referenciais teóricos, notadamente de pesquisas realizadas sobre os temas em debate, uso de instrumentos de observação da aprendizagem, com destaque para a aplicação da Escala Leuven de Avaliação do Nível de Envolvimento da Criança na Atividade ${ }^{1}$ (LAEVERS, 2014) e desenvolvimento de atividades práticas nas salas de aula.

\section{O diagnóstico: o que conhecemos sobre nossa aluna com deficiência intelectual?}

Não há como falar em avaliação da aprendizagem sem estabelecer estreita relação com o planejamento da ação pedagógica. É a avaliação que orienta a ação docente. É a partir dela que se propóem os caminhos que se pretende que o aluno percorra.

Com base nesse pressuposto, professores e pesquisadores se colocaram a conhecer a aluna com quem trabalham. Foi preciso que professores do ensino comum e da educação especial discutissem suas visôes sobre a aluna e identificassem outras formas de olhar sobre ela. Pois no que é atribuível a avaliação da aprendizagem do aluno com deficiência no contexto da escola comum "[...] muitas crianças e adolescentes são recebidos como se estivessem desprovidos completamente de algo que é essência da pessoa, ou seja, sua condição de sujeito aprendente. (FREITAS, 2013, p. 81).

Ao se entender que os alunos com deficiência que entram na sala comum apresentam uma história de possibilidades, a primeira etapa do processo de discussão do instrumento comum de avaliação foi descobrir que histórias esses sujeitos têm.

Para isso, no primeiro eixo da formação voltado ao diagnóstico, as discussóes estavam voltadas ao modo como Joana se colocava nos grupos escolares a que pertence, como interagia com professores e colegas, como os professores e colegas intera- 
giam com ela, como lidava com o conhecimento, o que demonstrava conhecer e qual seu nível de envolvimento nas atividades. Essas discussões buscavam ainda mapear as principais necessidades da aluna e conhecer o nível de interação entre os professores do ensino comum e da educação especial.

Desse modo, o foco foi conhecer juntos a aluna referência da pesquisa e chegar a um entendimento sobre o que ela conhece e o modo como aprende. Nessa experiência conjunta professores se aproximaram do conhecimento sobre a criança e dos percursos que faz para aprender. Estes revelaram, nas suas discussóes, que Joana é tímida, não se manifesta em sala de aula e não interage com os colegas. Porém, no AEE seu comportamento é diferente: apesar da timidez, toma iniciativa em colocarse diante de situaçóes e atividades fazendo interaçóes com pelo menos uma colega, como é possível perceber nos comentários de dois professores participantes da pesquisa $^{2}$ :

Sujeito 02-EC: É muito reservada, mesmo sendo chamada nos grupos, ela náo interage.

Sujeito 05-EE: Na Sala de recursos fica à vontade com a professora. Começa diálogo sobre situaçôes pontuais para interagir comigo. [...] Colegas agem normalmente com ela.

Ao aplicar a Escala Leuven de Envolvimento (LAEVERS, 2014) adaptada para a pesquisa, os professores perceberam que o envolvimento de Joana nas atividades que envolviam maior leitura, escrita, produção e raciocínio estava no nível 3, que é aquele em que "a criança desenvolve atividade, mas sem envolvimento" (LAEVERS, 2014, p.160). Em atividades práticas como em educaçáo física e em arte, seu envolvimento com a atividade chegou ao nível 5 em que "há engajamento total expresso pela concentração e absorção absoluta pela atividade" (LAEVERS, 2014, p.161), como demonstrado no depoimento dos professores:

Sujeito 04-EC - Então dá a impressão que a arte e educação física, o que é prático ela vai melhor.

Sujeito 10-EE - [No exercício] prático e coletivo.

Parte dessa situação que envolve as relaçôes da aluna com o ambiente escolar e de aprendizagem se deve também as formas de ensinar e de avaliar usadas pelos professores da sala de ensino comum.

As discussões sobre o diagnóstico possibilitaram aos professores uma reflexão sobre as diferentes manifestaçóes de Joana na sala de aula comum e na sala do AEE. Questionavam-se sobre suas iniciativas em iniciar conversas com a professora do AEE e sua aparente indiferença na sala de aula diante dos colegas. Observaram que a aluna apresenta possibilidades de expressão diferenciadas e que diagnósticos não podem ser definitivos. Desses debates retiram novas iniciativas para observar Joana em diferentes contextos.

Por este motivo, a partir do observado, a formação foi direcionada, ao pensar e ao agir dos professores em relação a aluna com deficiência intelectual. Nesse momento todos os professores juntos, do ensino comum e da educaçáo especial, passaram 
a olhar Joana e também seus demais alunos, sob outra perspectiva, refletindo sobre suas práticas e posicionamentos em diferentes contextos, sobre o processo de ensino e aprendizagem nesses espaços e sobre possibilidades outras de avaliação de seus alunos.

\section{Quais as possibilidades de redimensionar o olhar sobre a aprendizagem?}

No segundo momento da formação, o foco da discussão e dos estudos se concentrou em três eixos: a) a crítica ao modelo existente de PAEE; b) as pesquisas sobre outras possibilidades de Plano de Atendimento Educacional; c) as experiências que movimentam o olhar sobre a aprendizagem.

A análise do Plano de Atendimento Educacional Especializado utilizado no AEE serviu como referência para que o grupo observasse o modelo existente, seus elementos e constituição. Os professores foram divididos em pequenos grupos para que pudessem conversar entre si sobre o PAEE que tinham em mãos. Na divisão dos grupos atentou-se para que os professores com formação ou experiência em educação especial ficasse cada um em um grupo, a fim de coordenar as discussóes.

Para esse exercício de análise do modelo existente, os professores tiveram acesso a três outros modelos de Plano de Atendimento Educacional, frutos de pesquisas publicadas. Foi realizada uma análise comparativa destes modelos, de modo a identificarem elementos comuns e elementos diferenciados que poderiam vir a fazer parte do modelo a ser construído, melhorando sua funcionalidade. Destacaram que em um dos planos analisados, professores do ensino comum e especial, planejam em conjunto e isto foi considerado um diferencial bastante relevante. Concluíram que embora houvesse aspectos a serem contemplados o Plano adotado pela escola não diferia muito dos demais.

Após os encontros voltados a análise do PAEE vigente e da sua crítica, foi proposto aos professores que realizassem com a aluna referência, uma atividade de dramatização em que ela, junto de um grupo de alunos simulassem alguma situação cotidiana. Quando das discussóes sobre como ocorreu a atividade e como Joana se portou, os professores concluíram que o envolvimento da aluna em atividades coletivas e que exigiam colaboração é que gerou maiores possibilidades de expressão e que experiências como estas levaram todo o grupo a atuar de maneira mais efetiva.

Com o propósito de levar o grupo de professores a perceber a necessidade de movimentar o olhar sobre a aprendizagem, foi realizada uma atividade de jogo, denominado "Base 3", que exigia a elaboração de conceitos matemáticos de potenciação. Por meio dessa experiência, os professores puderam perceber que uma mesma atividade gera modos diferenciados de pensar, elaborar conceitualmente e demonstrar o que aprendeu.

Essas experiências que mesclaram análise crítica de um instrumento de avaliação (aliada ao estudo e à discussão de pesquisas sobre diferentes tipos de instrumentos), aplicação de atividades colaborativas de dramatização com os alunos e vivência pessoal de experiências coletivas de elaboração de conceitos por meio de um jogo, 
foram profícuas no sentido de movimentar o olhar dos professores sobre as aprendizagens de seus alunos, notadamente da aluna com deficiência intelectual. O principal objetivo nessa etapa era estudar, refletir, observar e viver experiências coletivas de colaboraçáo e de análise crítica do ensino e aprendizagem.

\section{Que conceitos, critérios e práticas devem ser levados em conta na construção mediada e colaborativa de um instrumento comum de avaliação?}

Após a discussão e análise de quatro modelos de Planos de Atendimento Educacional cujas nomenclaturas variam de acordo com autores e natureza de estudos, estruturou-se coletivamente o instrumento de avaliação da aprendizagem pelos professores do ensino regular e especial. Mais do que ser elaborado coletivamente, trata-se de um instrumento de avaliação mediado e colaborativo em que professores observam, registram, descrevem, planejam e avaliam a aprendizagem do aluno como um todo, sem compartimentar seus avanços e aprendizagens por disciplinas ou áreas.

$\mathrm{O}$ instrumento de avaliação construído foi denominado como Plano Colaborativo de Atendimento Educacional - PCAE. Foi assim denominado pelos participantes da pesquisa por entenderem-no Colaborativo não só por ter sido organizado em colaboração pelo grupo, mas principalmente pelo que pretende: ser instrumento de colaboração entre professores do ensino comum e especial na escolarização de aluno com deficiência no contexto da inclusão escolar. Optou-se por tirar os termos especializado por entender que isso direcionava apenas para a educação especial e, o individualizado por já entendê-lo implícito em sua propositura a coletividade, assim como para que se pudesse ampliar sua abrangência para além do atendimento especializado.

A construção do PCAE levou em conta critérios orientadores como:

- Observar e registrar o processo de aprendizagem do aluno no ensino comum e no AEE. Refere-se ao olhar atento dos percursos do aluno para aprender e à observaçáo cuidadosa das peculiaridades dos alunos em relaçáo às suas disciplinas. Tais observaçóes passaram a ser registradas em documento único de acesso a todos os professores do aluno.

- Considerar que, o que o aluno sabe é o "marco zero" para sua aprendizagem e não o ponto final. $\mathrm{O}$ grupo assumiu que ao se avaliar o aluno com deficiência, é preciso considerar e comparar sua aprendizagem com ele mesmo e náo com a turma.

- Definir em conjunto o objetivo geral da aprendizagem do aluno. Entendeu-se que os objetivos de escolarizaçáo para o aluno com deficiência podem (e devem) ser estabelecidos conjuntamente entre os professores. $\mathrm{O}$ importante é que se defina entre todos os professores da turma, quais as metas estabelecidas para este aluno.

- Dispor do Plano em ambiente virtual para acesso e registro simultâneo e remoto por todos os professores. Ao se pensar um Plano que fosse colaborativo e acessível a todos os professores, que pudesse estar disponível a cada um no tempo em que este tem para suas atividades pedagógicas, de imediato surgiu o consenso de que o mesmo deveria ser compartilhado por todos em ambiente virtual, permitindo 
que suas alteraçóes e atualizaçóes sejam visualizadas a qualquer tempo e lugar graças a ferramentas tecnológicas.

- Definir estratégias que cada professor utilizará, em um mesmo documento, de modo que todos conheçam o que todos estão fazendo. Cada professor registra as estratégias de aprendizagem e de avaliação que utiliza em sua disciplina durante a ação, que podem ser compartilhadas com os demais. Será essa troca de informaçóes simultâneas, no decorrer do período letivo, que efetivará o acesso ao currículo e a aprendizagem do aluno.

- Registrar a qualquer tempo, os avanços observados durante o período letivo, não precisando ser apenas em momentos de pós-avaliação. O registro se dá a partir de itens, podendo identificar quando o avanço é no desenvolvimento global do aluno ou em sua aprendizagem curricular (nas disciplinas).

- Observar e evidenciar os sinais e níveis de envolvimento do aluno na realização das atividades. Consiste em realizar apontamentos dos sinais de envolvimento do aluno na aprendizagem observados durante o processo. Para isso toma-se como base a Escala de Avaliação do Envolvimento de Leuven (LAEVERS, 2014).

- Alterar o planejamento das atividades tendo em conta os avanços e os níveis de envolvimento observados. Uma vez que o plano está em constante movimento pelo preenchimento, anotaçóes e registros contínuos e simultâneos ao processo de aprendizagem, suas alteraçôes se darão a qualquer tempo, permitindo o acompanhamento e avaliação simultânea do aluno.

- Emitir parecer descritivo sobre o processo de escolarização. Ao final do período letivo a equipe de profissionais envolvida com o aluno emite parecer descritivo fundamentado nos avanços do aluno, suas dificuldades, enfim, sua trajetória de aprendizagem. É necessário ainda que ofereça subsídios para encaminhamentos, sugestóes e possibilidades de intervenção pedagógica para o próximo período.

Uma vez que o Plano elaborado é um documento a ser preenchido por muitas mãos, o professor do AEE tem relevante participação nesse processo de observação e registros das atividades do aluno com deficiência intelectual. Devido ao fato de ser ele o professor com maior contato e relação com o aluno, cabe-lhe coordenar o trabalho de preenchimento do PCAE, prestando informaçóes, estabelecendo contato com os professores do ensino comum e também auxiliando os professores com as práticas por eles anotadas.

A partir de construção final do instrumento os professores envolvidos trabalharam na elaboração de um Manual de Orientaçóes para o Preenchimento do Plano como estratégia de garantir maior praticidade e exequibilidade do instrumento. $\mathrm{O}$ manual tem o propósito de viabilizar o acesso aos professores que venham a assumir turmas com alunos com deficiência na escola. 


\section{Conclusão}

Apesar dos vários estudos já encontrados sobre avaliação da aprendizagem de alunos com deficiência intelectual, a pesquisa sobre a construção mediada e colaborativa de instrumento de avaliação da aprendizagem desse público, em coparticipação de professores dos anos finais do ensino fundamental e de professores de educação especial, revelou a carência de estudos na área.

A Lei indica a necessidade de planejar a atuação pedagógica no AEE em articulação com o ensino comum, mas não especifica a necessidade de uma ação planejada, colaborativa e mediada do planejamento. Ao olhar o aluno com deficiência como sujeito capaz de aprender, nada melhor para ele que todos seus professores o conheçam como aluno da escola, e não como aluno do $\mathrm{AEE}$ ou da turma em que está matriculado.

Daí a riqueza do presente estudo. A experiência construída de maneira reflexiva e coparticipativa: revela a potência do Plano Colaborativo de Atendimento Educacional como instrumento de avaliação sistemática da aprendizagem do aluno com deficiência inserido no ensino comum.

Para que o caráter de colaboração entre os professores se dê ao longo do período ao qual o Plano de destina, o mesmo foi disponibilizado em formato online e acompanhado pelo Manual de Orientaçôes para o Preenchimento com vistas a facilitar $\mathrm{o}$ acesso e preenchimento pelos professores que não fizeram parte da pesquisa, mas que têm ou terão alunos com deficiência em suas turmas.

Mostrar aos professores do ensino comum, e também da educaçáo especial, que o trabalho colaborativo entre eles traz possibilidades de ampliaçáo de intervenções e, principalmente, intervençóes melhores, junto a esses alunos, possibilitou perceber que o descompasso entre as prerrogativas das políticas de educação inclusiva e a cultura escolar vigente, tende a diminuir quando o foco da aprendizagem está direcionado para busca de respostas fundamentadas e a construção de alternativas metodológicas consistentes que a escola deve/pode dar a esses sujeitos.

\section{Referências}

BANDEIRA, Hilda Maria Martins. Pesquisa colaborativa: unidade pesquisa-formação. In: IBIAPINA, Ivana Maria Lopes de Melo; BANDEIRA, Hilda Ma Martins; ARAÚJO, Francisco Antonio Machado (Orgs.). Pesquisa colaborativa: multirreferenciais e práticas convergentes. Teresina-PI: EDUFPI, 2016. EBOOK.

BOTERF, Guy Le. Pesquisa Participante: propostas e reflexões metodológicas. In.: BRANDÁO, Carlos Rodrigues (Org.). Repensando a pesquisa participante. São Paulo: Brasiliense, 1999.

BRASIL. Ministério da Educaçấo. Política Nacional de Educaçáo Especial na Perspectiva da Educação Inclusiva. Brasília: MEC/SECADI, 2008. Disponível em <http://portal.mec.gov.br/index.php?option=com_do$\mathrm{cman} \&$ view=download\&alias=16690-politica-nacional-de-educacao-especial-na-perspectiva-da-educacao-inclusiva-05122014\&Itemid=30192>. Acesso em 22 mai. 2017.

BRASIL. Ministério da Educação. Conselho Nacional de Educação. Resolução no 4, de 2 de outubro de 2009. Institui Diretrizes Operacionais para o Atendimento Educacional Especializado na Educação Básica, modalidade Educação Especial. Brasília: MEC/CNE, 2009. Disponível em <http://portal.mec.gov.br/dmdocuments/ rceb004_09.pdf>. Acesso em 22 mai. 2017.

DUSSEL, Inés. A montagem da escolarização: discutindo conceitos e modelos para entender a produção histórica da escola moderna. Revista Linhas, Florianópolis, v. 15, n. 28, p. 250-278, jan./jun. 2014. Título original: 
The Assembling of Schooling: discussing concepts and models for understanding the historical production of modern schooling. Traduzido por Fernando Coelho, com revisão técnica de Vera Lucia Gaspar da Silva e Geovana Mendonça Lunardi Mendes.

FARIA FILHO, Luciano Mendes de; VIDAL, Diana Gonçalves. Os tempos e os espaços escolares no processo de institucionalização da escola primária no Brasil. Rev. Bras. Educ. [online]. 2000, n.14, pp.19-34.

FREITAS, Marcos Cezar de. O aluno incluído na educaçáo básica: avaliação e permanência. 1 ed. São Paulo: Cortrez, 2013 (Coleçáo educaçáo e Saúde, no 9).

GLAT, Rosana; PLETSCH, Márcia Denise. (Orgs.) Estratégias educacionais diferenciadas para alunos com necessidades especiais. Rio de Janeiro: EdUERJ, 2013.

IBIAPINA, Ivana Maria Lopes de Melo. Reflexões sobre a produção do campo teórico-metodológico das pesquisas colaborativas: gênese e expansão. In: IBIAPINA, Ivana Maria Lopes de Melo; BANDEIRA, Hilda Ma Martins; ARAÚJO, Francisco Antonio Machado. (Orgs.). Pesquisa colaborativa: multirreferenciais e práticas convergentes. Teresina-PI: EDUFPI, 2016. EBOOK, baixado em 09 jul 2017.

LAEVERS, Ferre. Fundamentos da educação experiencial: bem-estar e envolvimento na educação infantil. Trad.: Tina Marie Stutzman. Est. Aval. Educ., São Paulo, v. 25, n. 58, p. 152-185, maio/ago. 2014.

PROSSER, Jon. The Evolution of School Culture Research, in J. Prosser (Ed.) School Culture. London: Sage, 1999. http:// dx.doi.org/.4135/9781446219362.nl

SILVA, Cristiane da; HOSTINS, Regina Célia Linhares; MENDES, Regina da Silva. O lugar do Atendimento Educacional Especializado nas práticas culturais de escolarização em contextos de inclusão escolar. Revista Linhas. Florianópolis, v. 17, n. 35, p. 10-29, set./dez. 2016.

SKRTIC, Thomaz M. A justiça Institucionalizada: construçâo e uso da deficiência na escola. In: BUENO, José Geraldo Silveira; MUNAKATA, Kazumi; CHIOZZINI, Daniel Ferraz. (Orgs.). A escola como objeto de estudo: escola, desigualdades, diversidades. 1 ed. Araraquara, SP: Junqueira \& Marin, 2014.

\section{Notas}

'A Escala é constituída por uma lista de nove sinais característicos do envolvimento: concentraçăo, energia, complexidade e criatividade, expressão facial e postura, persistência, precisão, tempo de reação, comentários verbais e satisfação, e por uma escala de cinco pontos que mensuram o envolvimento do nível 1 ao nível 5.

${ }^{2}$ Para identificação dos sujeitos, mantendo o princípio da confidencialidade, foi usado numeração e as letras EC para identificação de professor do ensino comum e EE para professor da educação especial.

\section{Correspondência}

Alessandra de Fatima Giacomet Mello - Universidade do Vale do Itajaí (UNIVALI). R. Uruguai, 458, Centro, CEP: 88302-901, Itajaí, Santa Catarina, Brasil.

E-mail: alegmello@hotmail.com - reginalh@univali.br

Recebido em 25 de julho de 2018

Aprovado em 08 de agosto de 2018

\section{(c) (i) (8)}

This work is licensed under a Creative Commons Attribution-NonCommercial 4.0 International (CC BY-NC 4.0) 
